\title{
Gas Antisolvent Fractionation: a New Method to Obtain Enantiopure Compounds, a Case Study on Mandelic Acid
}

\author{
Márton Kőrösi ${ }^{1 *}$, Attila Sedon¹, Kinga Komka1', Tamás Sohajda², Edit Székely \\ 1 Department of Chemical and Environmental Process Engineering, Faculty of Chemical Technology and Biotechnology, \\ Budapest University of Technology and Economics, H-1111 Müegyetem rakpart 3. Budapest, Hungary \\ 2 CycloLab Cyclodextrin Research and Development Laboratory Ltd., H-1097 Budapest, Illatos út 7., Hungary \\ *Corresponding author, email: mkorosi@mail.bme.hu
}

Received: 01 December 2017, Accepted: 12 February 2018, Published online: 04 April 2018

\begin{abstract}
Micronization processes involving supercritical carbon dioxide are rapid methods to produce fine particles. They also might offer the possibility of using less organic solvent than conventional crystallization methods leading to an environmentally friendlier processing. The separation capabilities of such processes are now demonstrated on the diastereomeric resolution of mandelic acid using (R)-1-phenylethanamine as a resolving agent, utilizing the batch type gas antisolvent fractionation as the separation method. A detailed study was conducted on the effects of the operational parameters pressure (12-20 MPa), temperature $\left(35-55{ }^{\circ} \mathrm{C}\right)$ and co-solvent concentration (33-99 mg/ml). At $12 \mathrm{MPa}, 35^{\circ} \mathrm{C}$ and $99 \mathrm{mg} / \mathrm{ml}$ methanol concentration, a selectivity of 0.52 and a diastereomeric excess of $62 \%$ was reached. The same operational parameters were applied during the investigation of the recrystallization-based further purification of the diastereomeric salts, applying the resolving agent in molar equivalent quantity to a non-racemic mixture of mandelic acid. It has been found that the more stable (R)-1-phenylethylammonium-(R)-mandelate salt can be purified to de>98\% through four additional recrystallization steps following the initial, half-molar equivalent resolution step.
\end{abstract}

Keywords

supercritical carbon dioxide, optical resolution, enantiomer, chiral, recrystallization

\section{Introduction}

Separation techniques involved in almost every chemical manufacturing process are often solvent- and energy-intensive. For example, traditional crystallization (or recrystallization) processes often use large amounts of organic solvents, while having the product contaminated by traces of the mother liquor is still a problem to be addressed these days. The use of supercritical carbon dioxide in separation processes such as extraction can result in products of very high purity. However, the higher cost and safety requirements of such unit operations make their use typically only reasonable in case of products with a higher added value. [1] Similarly, antisolvent processes carried out using supercritical carbon dioxide are not yet widely applied in the industry, but they are intensively researched crystallization methods offering solvent-free, highly crystalline products in the (maximum) micrometer particle size range or even micronized composites having special properties. [2-5] The possibility to decrease the amount of the organic solvents used makes them environmentally friendly.
In the batch type gas antisolvent precipitation process a nearly saturated solution of the target compound is filled into an autoclave (Fig. 1 a) and pressurized with supercritical carbon dioxide. The organic solvent is chosen to be polar enough to dissolve the material to be precipitated but also to be able to form a homogenous phase mixture with supercritical carbon dioxide. During the formation of the above-mentioned mixture, the polarity of the solvent drops significantly thus the solubility of polar components is sharply decreased too. These effects allow the dissolved material to form solid (mostly highly crystalline) particles (Fig. 1 b). However, the organic solvent is still present in the high-pressure precipitation vessel, so an extractive washing step has to be applied using pure supercritical carbon dioxide (Fig. 1 c). After depressurization a visibly dry, powderous product can be collected (Fig. 1 d) having an excellent purity. Antisolvent processes (mostly scaled up variants like the semi-continuous supercritical antisolvent precipitation) allow controlling the main particle size 


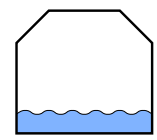

a)

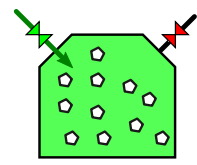

b)

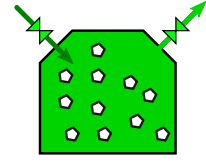

c)

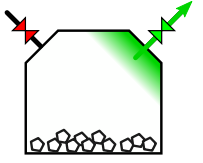

d)
Fig. 1 A stepwise, schematic explanation of the gas antisolvent fractionation process a) The organic solution of the compound to be precipitated is filled into the high-pressure vessel. b) Supercritical carbon dioxide is added, precipitation happens due to the polarity change of the solvent mixture. c) The undesired components and the organic solvent are extracted using pure supercritical carbon dioxide.

and achieving a very narrow particle size distribution. [2] Operational parameters (i.e. pressure ( $p$ [MPa]), temperature $\left(T\left[{ }^{\circ} \mathrm{C}\right]\right)$ and organic solvent concentration $\left(c_{s}[\mathrm{mg} /\right.$ $\mathrm{ml}])$ can be set to keep a certain fraction of a multi-component starting mixture dissolved in the organic solvent-carbon dioxide mixture and to be later extracted by the carbon dioxide stream. The general effects of the mentioned parameters on the solubility of other compounds in supercritical carbon dioxide are available in the literature. [6]

When besides precipitation it is also important to achieve selective separation, the technique is called gas antisolvent fractionation (GASF) (but other names can also be found in the literature like for example gas antisolvent extraction [7-9] etc.) and can be used as a simultaneous fractionation and micronization method.

Chiral compounds, the enantiomers of which often exhibit very different biological effects, are extensively used in various sectors of the chemical industry. The production of enantiomerically pure chemicals is still an intensively researched area. There are only very few methods yielding enantiopure compounds in one single step (e.g. highly selective asymmetric syntheses), thus it is necessary to find new ways of producing optically active compounds and to purify the non-racemic mixtures obtained in for example moderately stereoselective syntheses. A traditional yet still often applied method of enantiomeric separation is diastereomeric resolution. In case of chiral carboxylic acids and bases an appropriate resolving agent of the opposite chemical character is added and the forming diastereomeric salts can be separated by crystallization. It is well known that the application of half molar equivalent of resolving agent is the most efficient way to resolve racemates, while the recrystallization of the forming diastereomers is a straightforward procedure of diastereomeric further purification. [10, 11] It was discovered that the maximum optical purity that can be reached in a single resolution step correlates to the melting point eutectic composition of the racemate or the resolving agent, depending on which one is higher. [12] A limit corresponding to the melting point eutectic composition was also found in the recrystallization-based further purification of enantiomeric mixtures under atmospheric conditions. [11]

Certain types of supercritical carbon dioxide-involving processes for optical resolution have already been published. Supercritical carbon dioxide can be used as an extraction solvent [13-16], a reaction medium [17] or an antisolvent [18-20] as well. 98\% or higher enantiomeric excess values were achieved in certain cases only. [20-22] However, there is only limited information available on the applicability of antisolvent processes for the further purification by the antisolvent recrystallization of diastereomeric mixtures. [20, 23]

Mandelic acid is often used as a model molecule in investigations targeting chiral separation. [24-28] It is a frequently applied resolving agent itself. The diastereomeric salt of mandelic acid and $(R)$-1-phenylethanamine has already been the subject of resolution experiments with gas antisolvent precipitation from a dimethyl-sulphoxide - ethyl-acetate mixture, by half-equivalent, equivalent methods as well and by in situ salt formation too. In a system very similar to that presented above, Martín and Cocero achieved selectivity values ranging between 0.21 and 0.46 while the highest $d e$ achieved was $52 \%$. The results of Martín and Cocero were recalculated based on the total mass and component balance equations to match our calculation methods. In the cited paper effects of operational parameters were slightly addressed, and no further purification was performed. [19]

Our aim is to show the effects of the operational parameters (i.e. pressure ( $p[\mathrm{MPa}])$, temperature $\left(T\left[{ }^{\circ} \mathrm{C}\right]\right)$ and organic solvent concentration $\left(c_{s}[\mathrm{mg} / \mathrm{ml}]\right)$ in depth on the optical resolution of mandelic acid with $(R)-1$ phenylethanamine carried out using GASF as a separation method. Furthermore, the possibility of the further purification of the diastereomeric mixture is presented as well without liberating the acid from the diastereomeric salt, only by recrystallizing the latter.

\section{Materials and Methods}

\subsection{Materials}

Racemic mandelic acid (CAS 90-64-2; purity $>99 \%$ ) and both enantiopure $(R)-(-)$-mandelic acid (CAS 611-71-2; purity $>99 \%$ ) and $(S)$-mandelic acid (CAS 17199-29-0; 
purity $>99 \%$ ) were purchased from Sigma-Aldrich. $(R)-1-$ Phenylethanamine (CAS 3886-69-9, purity >99\%) was purchased from Merck. Carbon dioxide (purity $>99.9 \%$ ) used as an antisolvent was bought from Linde Gas Hungary and was used freshly distilled in our experiments. Methanol used both as an organic solvent to dissolve initial samples and as a trapping solvent was bought from Merck (purity $>99.9 \%$ ). Ethyl-acetate (purity $>99.5 \%$ ) was purchased from Merck, while dimethyl-sulphoxide (purity $>99.9 \%$ ) was obtained from Molar Chemicals.

\subsection{General description of the GASF experiments}

GASF experiments were carried out in a laboratory scale $(37 \mathrm{ml})$ autoclave (Fig. 2). First, $100 \mathrm{mg}$ of the enantiomeric mixture of mandelic acid was measured into a glass vial. This was either racemic, or a scalemic mixture of a desired $e e$, produced by mixing racemic and enantiomeric mandelic acid physically. Then enantiomerically pure $(R)-1$-phenylethanamine was added. Half molar equivalent of the $(R)$-amine $(39.8 \mathrm{mg})$ was used in the experiments aiming the investigation of the influence of the operational parameters and a molar equivalent of the enantiopure amine $(79.6 \mathrm{mg}$ ) was used in the further purification studies. Then, the mixture was dissolved in methanol and the homogenous solution was filled into the tempered laboratory autoclave. The quantity of methanol used was determined by mass in order to calculate its concentration in the autoclave. After assembling the high-pressure reactor it was filled with supercritical carbon dioxide to reach the desired pressure. The tempered syringe pump used to pressurize the reactor allowed us to determine the quantity of $\mathrm{CO}_{2}$ filled into the high pressure vessel. Pressurization was followed by 1-hour-long stirring and equilibration. Afterwards the reactor was washed with pure carbon dioxide, using a total volume of $\mathrm{CO}_{2}$ corresponding to approx. 3 times the volume of the reactor. In this step both the organic solvent and the dissolved components (mandelic acid and/or salt) were extracted and collected in a solvent trap. Solid particles were kept from being dragged out by a filter. After depressurization, a visibly crystalline, white material was collected from the reactor, which is referred to as the raffinate. The extract was collected by evaporation of the solvent from the trap. Starting materials and products were analyzed using chiral capillary electrophoresis, powder X-ray diffraction and scanning electron microscopy.

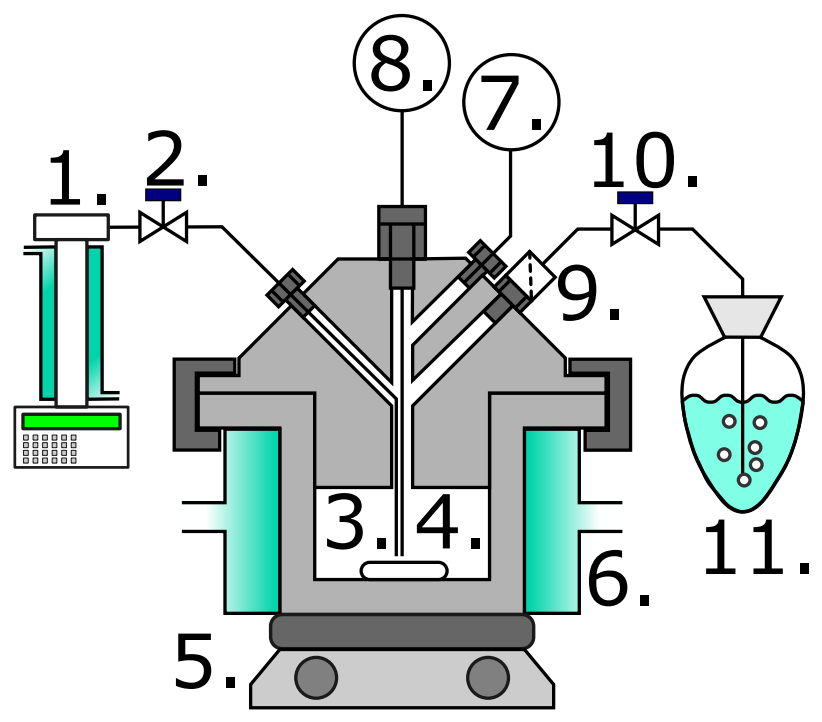

Fig. 2 A non-proportional, schematic depiction of the laboratory autoclave. 1. Teledyne ISCO 260D syringe pump; 2 . Regulator valve of carbon dioxide inlet; 3 . Tubing towards the bottom of the reactor serving a more thorough mixing; 4. Magnetic stirrer; 5. Magnetic motor; 6 . Thermosetting jacket operating with water; 7. Pressure transducer and digital manometer; 8. Thermocouple; 9. Metallic filter

( $2 \mu \mathrm{m}$ pore diameter); 10. Regulator valve of the outlet stream; 11. Solvent trap filled with methanol

\subsection{Capillary electrophoresis measurements}

Chiral capillary electrophoresis measurements were carried out to determine the diastereomeric (enantiomeric) composition of the products. The composition of initial enantiomeric mixtures of the further purification experiments was also confirmed. Measurements were carried out on an Agilent 7100 electropherometer fitted with a $50 \mathrm{~cm}$ long polyimide-covered uncoated silica capillary and a DAD detector, at $25^{\circ} \mathrm{C}$ and with $20 \mathrm{kV}$ applied to the column. pH 9 was ensured using a $50 \mathrm{mM}$ borate buffer. Peaks were detected at $200 \mathrm{~nm}$ and a reference wavelength of $320 \mathrm{~nm}$ was used. The chiral selector added to the buffer was 6-monodeoxy-6-monoamino-beta-cyclodextrin hydrochloride, a product of Cyclolab Ltd.

\subsection{Powder X-ray diffraction and scanning electron microscopy}

Powder X-ray diffraction investigations were done on a PANalytical X'pert Pro diffractometer. It is equipped with an X'celerator detector. The wavelength of the X-ray was $1.5408 \AA(\mathrm{Cu} \mathrm{K} \alpha)$ and $40 \mathrm{kV}$ and $30 \mathrm{~mA}$ were applied to the X-ray tube. Scanning was performed between the $2 \Theta$ angles of 4 and $46^{\circ}$, with a total scanning time of 
10 minutes. The results of the powder X-ray diffraction measurements are discussed in the supplement.

Scanning electron microscopy investigations were carried out on a JEOL JSM 5500-LV electron microscope, using a secondary electron detector, and applying $20 \mathrm{kV}$ accelerating voltage, in order to estimate the range of the particle size. Sample images can be found in the supplement. In order to make the surface of the samples conductive, an approximately $10 \mathrm{~nm}$ thick $\mathrm{Au}-\mathrm{Pd}$ coating was applied.

\subsection{Evaluation and calculation methods}

Crystalline (i.e. raffinate) samples were characterized by their diastereomeric composition and their quantity. The diastereomeric purity can be described with Eq. (1).

$d e_{r}=e e_{\text {acid }}=\left|\frac{A_{R}-A_{s}}{A_{R}+A_{s}}\right|$

The salts of mandelic acid and 1-phenylethanamine dissociate under the conditions of the capillary electrophoresis measurements, thus the acid and the base are detected separately. Therefore the diastereomeric excess (de) value of the products equals the average enantiomeric excess of the acid found in the sample. In Eq. (1) $A$ denotes the peak areas of the enantiomers, while indices $R$ and $S$ stand for the enantiomers of mandelic acid. The peak area of 1-phenylethanamine is not used in the calculation.

Raffinate yields $\left(Y_{r}\right)$ were calculated using Eq. (2).

$$
Y_{r}=\frac{m_{r}}{m_{b}+M R \cdot m_{a}}
$$

$M R$ stands for the molar ratio between the base (resolving agent) and the acid, $m$ denotes mass, while indices $r, b$ and $a$ stand for "raffinate", "base" and "acid" respectively. In the denominator of the equation the maximal mass of the raffinate is calculated assuming a $100 \%$ conversion of the salt-forming reaction. Thus, during the calculation of the theoretical maximum of the raffinate mass, the diastereomeric salts are both assumed insoluble in the carbon dioxide-organic solvent mixture while the acid remaining free is assumed to be completely extracted. Obviously neither of these assumptions can be true (e.g. the $<100 \%$ yields of further purification experiments) but this equation gives a standardized and well comparable reference in case of both half molar equivalent resolution experiments and further purification studies. It must be noted however, that the two types of experiments cannot be compared based on their yields calculated using Eq. (2).
By multiplying the two quantities defined above we get the selectivity $\left(S_{r}\right.$; Eq. (3)), a value characterizing the resolution efficiency, applicable in case of experiments starting from a racemate.

$S_{r}=Y_{r} \cdot d e_{r}$

A similar value used in case of further purification experiments is the efficiency of diastereomeric enrichment $(E D E$; Eq. (4)). In the denominator de denotes the diastereomeric excess of the initial sample before recrystallization.

$$
E D E=Y_{r} \cdot \frac{d e_{r}}{d e_{i}}
$$

\section{Results and Discussion}

The aim of our research work was to conduct experiments throughout the whole chiral resolution process, starting with racemic mandelic acid and ending with discussing a new method of producing its enantiopure form applying GASF as the separation method. This involves performing chiral resolution of mandelic acid using the resolving agent $(R)$-1-phenylethanamine in half molar equivalent quantity, then studying the possibility of further purification applying the resolving agent in molar equivalent quantity (Fig. 3). Starting from non-racemic mandelic acid, the latter simulates the recrystallization of diastereomeric salts obtained from an initial resolution.

Sadly we could not reproduce the results of Martín and Cocero [19] because of some differences in the equipments used in the two laboratories. Namely, the autoclave described in the cited article has its filter attached at the bottom, allowing to drive out the residue of the organic solvent even if there are an expanded organic solvent and a fluid phase as well above the precipitate. Our autoclave has the filter attached to the top which makes it necessary to form a homogenous, single fluid phase over the precipitate in order to extract the organic solvent. Thus, experiments were conducted using a different solvent (methanol).

\subsection{Resolution of racemic mandelic acid}

Parametric optimization was carried out in the ranges of pressure $(p ; 12-20 \mathrm{MPa})$, temperature $\left(T ; 35-55{ }^{\circ} \mathrm{C}\right)$ and organic solvent concentration $\left(c_{s} ; 33-99 \mathrm{mg} / \mathrm{ml}\right)$ provided by the experimental equipment. A $2^{3}$ full factorial experimental design was carried out to describe the parametric effects and choose an appropriate combination of them for the further purification of the diastereomeric salts (Table 1). 


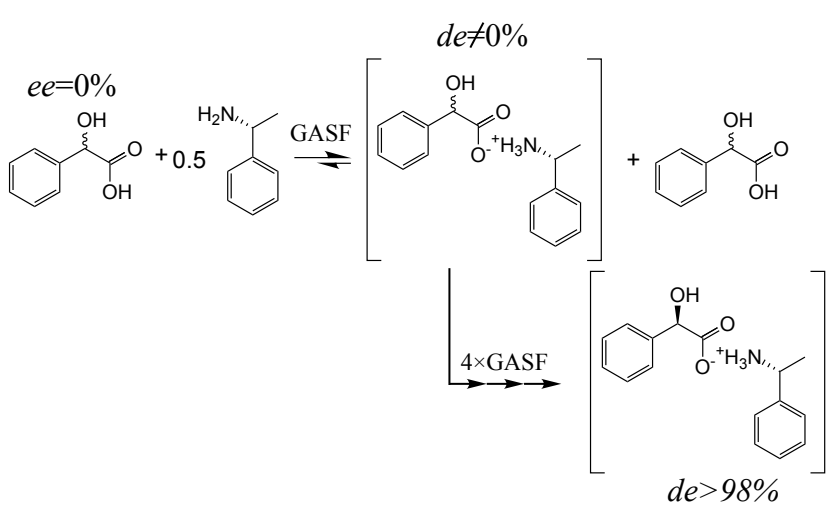

Fig. 3 The reaction scheme of the resolution carried out with half molar equivalent resolving agent and that of the later recrystallization of the diastereomeric salt

Table 1 A list of the half-molar equivalent resolution experiments carried out during the parametric optimization. *The experiment resulted in a wet raffinate and no chiral discrimination.

\begin{tabular}{|c|c|c|c|c|c|}
\hline $\begin{array}{c}p \\
{[\mathrm{MPa}]}\end{array}$ & $\begin{array}{c}T \\
{\left[{ }^{\circ} \mathrm{C}\right]}\end{array}$ & $\begin{array}{c}c_{s} \\
{[\mathrm{mg} / \mathrm{ml}]}\end{array}$ & $\begin{array}{c}Y_{r} \\
{[\%]}\end{array}$ & $\begin{array}{l}d e_{r} \\
{[\%]}\end{array}$ & $\begin{array}{c}S_{r} \\
{[-]}\end{array}$ \\
\hline \multicolumn{6}{|c|}{ Original $2^{3}$ experimental design } \\
\hline 16 & 45 & 66 & 79.2 & 60.0 & 0.48 \\
\hline 16 & 45 & 66 & 75.8 & 58.2 & 0.44 \\
\hline 16 & 45 & 66 & 79.0 & 59.6 & 0.47 \\
\hline 12 & 35 & 33 & 95.0 & 42.0 & 0.40 \\
\hline 12 & 35 & 99 & 82.7 & 62.4 & 0.52 \\
\hline *12 & 55 & 33 & 119.4 & 11.2 & 0.13 \\
\hline$* 12$ & 55 & 99 & 109.7 & 0.4 & 0.004 \\
\hline 20 & 35 & 33 & 93.9 & 48.0 & 0.45 \\
\hline 20 & 35 & 99 & 71.4 & 66.8 & 0.48 \\
\hline 20 & 55 & 33 & 100.7 & 48.0 & 0.48 \\
\hline 20 & 55 & 99 & 48.7 & 64.2 & 0.31 \\
\hline \multicolumn{6}{|c|}{ Additional experiments } \\
\hline 12 & 37 & 99 & 57.9 & 63.2 & 0.37 \\
\hline 12 & 40 & 99 & 57.9 & 57.4 & 0.33 \\
\hline$* 12$ & 45 & 99 & 117.0 & 0.2 & 0.002 \\
\hline
\end{tabular}

Three repetitions were performed in the centrum (at $16 \mathrm{MPa}, 45^{\circ} \mathrm{C}$ and $66 \mathrm{mg} / \mathrm{ml}$ methanol concentration). In optical resolution processes it is mostly the crystalline product that is collected and purified, so we also focused on the properties of the raffinate (i.e. yield, diastereomeric purity and selectivity). Results were evaluated using the software Statistica (version 13.0).

At $12 \mathrm{MPa}$ and $55^{\circ} \mathrm{C}$ (at both solvent concentrations), the crystalline product was visibly wet after the standardized washing step and showed no chiral discrimination. To determine the highest temperature that can be used at
$12 \mathrm{MPa}$, three additional experiments were carried out at $12 \mathrm{MPa}$ and $99 \mathrm{mg} / \mathrm{ml}$ methanol concentration (Table 1). The $d e_{r}$ values obtained at $12 \mathrm{MPa}$ and $99 \mathrm{mg} / \mathrm{ml}$ methanol concentration are plotted against the temperature in Fig. 4. Between $35{ }^{\circ} \mathrm{C}$ and $40{ }^{\circ} \mathrm{C}$, a slight decrease can be observed in the $d e_{r}$, while at $45^{\circ} \mathrm{C}$ and $55^{\circ} \mathrm{C}$ the raffinate showed no diastereomeric excess, implying a limit in the application of the functions obtained with regression above $40^{\circ} \mathrm{C}$. At higher temperatures the raffinate also seemed to contain some of the initial solvent.

This is likely to be the effect of the fluid phase over the precipitate being non-homogeneous. The reason is supposedly the increased critical pressure of the multicomponent mixture compared to the methanol $-\mathrm{CO}_{2}$ binary mixture having a critical pressure estimated in the range 9.5 to $11 \mathrm{MPa}$ at the temperature range of the current study. $[29,30]$ If there are three phases, the extraction cannot be carried out effectively.

The statistical evaluation also confirmed our suspicion as the measurement points at $12 \mathrm{MPa}$ and $55^{\circ} \mathrm{C}$ showed a critical (irregular) behavior. The response function contains discontinuity. The continuous part which contains the remaining points and the additional experiments in Table 1 is to be described using a regression method, as the advantageous properties of usual designs are not applicable. The detailed description of the regression method is presented in the supplement.

The surface fitted to the diastereomeric excess of the raffinates $\left(d e_{r}\right)$ is shown in Fig. 5.

The fitted surface suggests that an increase in pressure results a slight increase in the diastereomeric excess of the crystalline product, while the organic solvent concentration has an optimum value between 90 and $99 \mathrm{mg} / \mathrm{ml}$.

The experiment resulting in the highest raffinate de $(66 \%)$ was conducted at $20 \mathrm{MPa}, 35^{\circ} \mathrm{C}$ and $99 \mathrm{mg} / \mathrm{ml}$ of methanol concentration, but a slightly higher selectivity (0.52) was achieved at $12 \mathrm{MPa}, 35^{\circ} \mathrm{C}$ and $99 \mathrm{mg} / \mathrm{ml}$ despite the lower diastereomeric excess $(62 \%)$ due to the higher yield $(83 \%)$. According to the SEM images presented in the supplement, the raffinate obtained at $12 \mathrm{MPa}, 35{ }^{\circ} \mathrm{C}$ and $99 \mathrm{mg} / \mathrm{ml}$ methanol concentration contained sheet-like crystals with widths ranging from $2 \mu \mathrm{m}$ to $25 \mu \mathrm{m}$ and lengths between approximately $20 \mu \mathrm{m}$ and $140 \mu \mathrm{m}$. Although the further purification of the diastereomeric salt could be best observable using the parameters resulting in the highest purity, from a technological point of view it could be beneficial to apply milder conditions because of the lower risk of high pressure and the lower $\mathrm{CO}_{2}$ consumption. 


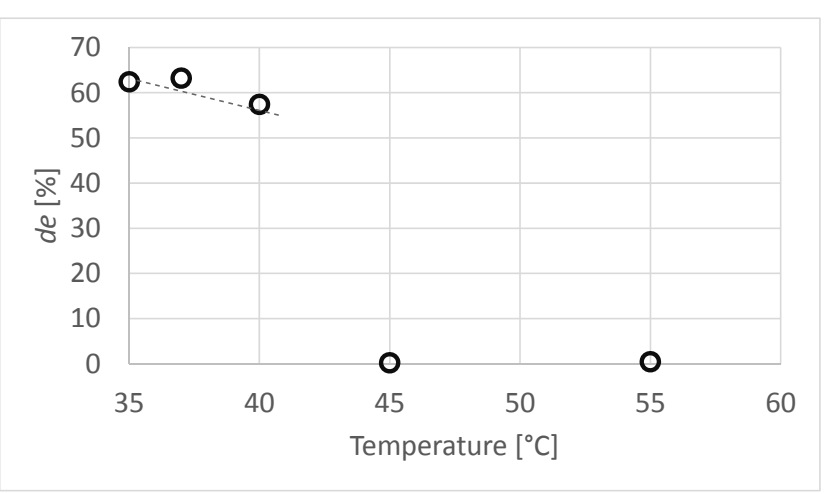

Fig. 4 The effect of temperature on the diastereomeric excess at $12 \mathrm{MPa}$ and $99 \mathrm{mg} / \mathrm{ml}$ solvent concentration
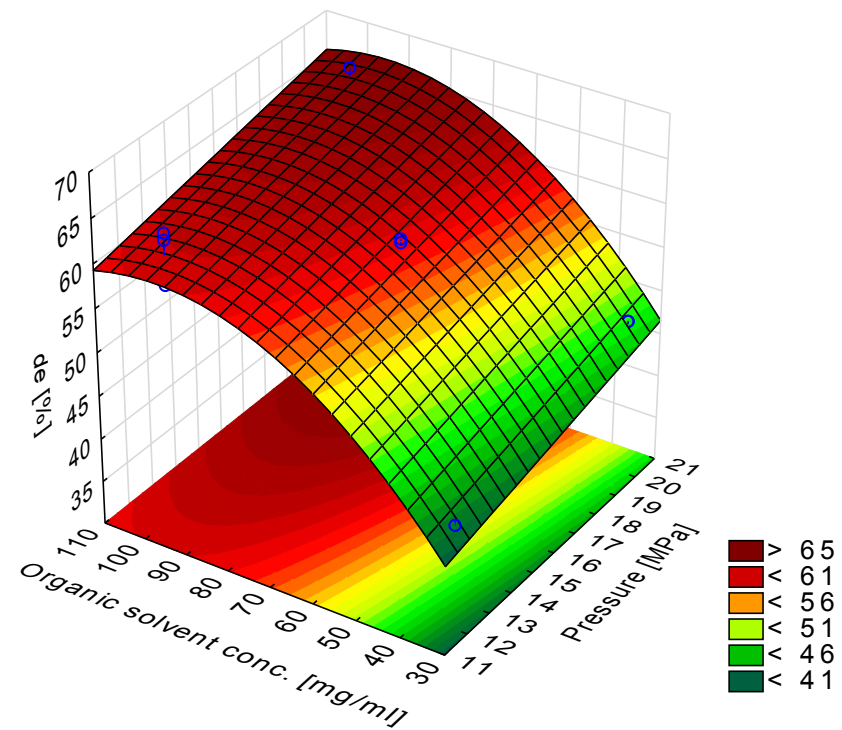

Fig. 5 The diastereomeric excess of the raffinates plotted against the organic solvent concentration and pressure at $40{ }^{\circ} \mathrm{C}$

A comparison can be made with the experiments of Martín and Cocero [19] to the results presented in this paper. Although the raffinate yields of our experiments fall back compared to those mentioned in the cited paper, the higher $d e_{r}$ values are responsible for the often higher selectivity results. Besides the more efficient and selective extraction step, methanol is more convenient to use than the mixture of ethyl-acetate and DMSO.

\subsection{Purification of the obtained diastereomeric mixtures}

As it is not possible to achieve an enantiopure product in a single resolution step, purification of the obtained diastereomeric salts is necessary. Results of recrystallization by the GASF method were investigated in detail at $12 \mathrm{MPa}, 35^{\circ} \mathrm{C}$, and $99 \mathrm{mg} / \mathrm{ml}$ methanol concentration and salts of different initial diastereomeric excess values.
The purification results are presented in Fig. 6. Five repetitions were carried out with an initial diastereomeric excess of 0 . The margin of error represents the standard deviation of these measurements. The dashed curve is not the result of a mathematical fitting, it is just a guide for the eye.

The diagram demonstrates that the more stable $(R)$-phenylethylammonium- $(R)$-mandelate salt can be purified using GASF as a method of recrystallization. The diagram can be used in a similar way to equilibrium curves in distillation: by constructing steps from the initial composition towards the aimed one, it is possible to estimate the number of recrystallization processes needed. However, it is important to notice that in this case, the compositions of initial materials and actual products are shown in the diagram and not the compositions of phases in equilibrium. The steps constructed in the diagram of Fig. 6 (dotted line) show a purification process initiated by a resolution step using half molar equivalent of the resolving agent.

The efficiency of diastereomeric enrichment ( $E D E$; Eq. (4)) describes the further purification both in terms of yield and purification rate: the higher, the better. Fig. 7 shows a minimum between 20 and $80 \%$ initial $d e$. At $d e_{0}=20 \%$, the ratio of the diastereomeric excesses is large, while at $80 \%$ the high yield is what causes the high $E D E$ values. The high yield can be explained by the larger amount of the more stable (less soluble) salt in the initial mixture.

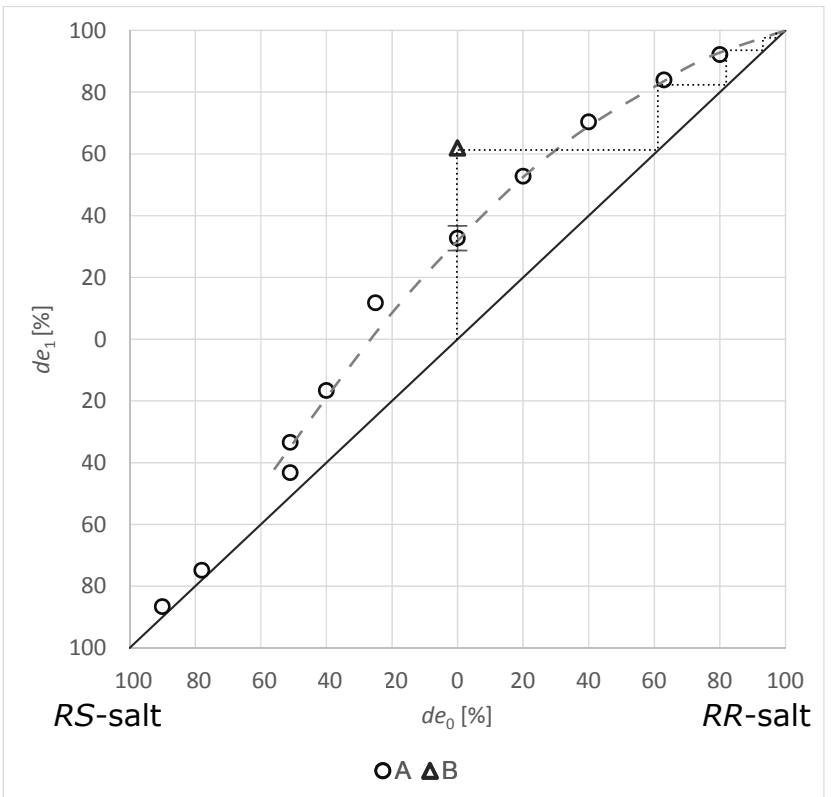

Fig. 6 Diastereomeric enrichment (initial $d e$ - raffinate de) diagram of the 1-phenylethylammonium-mandelate salts. A) Further purification results by GASF; B) Best resolution result using half molar equivalent of $(R)$-1-phenylethylamine 


\section{Conclusions}

Gas antisolvent fractionation is demonstrated to be an effective method of both chiral resolution and recrystallization-based enrichment of diastereomeric mixtures. The effects of the operational parameters (pressure, temperature, organic solvent concentration) have been studied using the mandelic acid $(R)$-1-phenylethanamine system. Using half molar equivalent of the resolving agent, dissolved mandelic acid was separated from the diastereomeric salt of low solubility, resulting in a selectivity value of approx. 0.52 (at $12 \mathrm{MPa}, 35{ }^{\circ} \mathrm{C}$ and $99 \mathrm{mg} / \mathrm{ml}$ methanol concentration). Recrystallization-based diastereomeric enrichment was carried out. In this case, separation is based on the different solubility of the diastereomeric salts. The recorded product $d e-$ initial de diagram allows

\section{References}

[1] Knez, Ž., Markočič, E., Leitgeb, M., Primožič, M., Knez Hrnčič, M., Škerget, M. "Industrial applications of supercritical fluids: A review", Energy, 77, pp. 235-243. 2014. https://doi.org/10.1016/j.energy.2014.07.044

[2] Knez, Ž., Knez Hrnčič, M., Škerget, M. "Particle Formation and Product Formulation Using Supercritical Fluids", Annual Review of Chemical and Biomolecular Engineering, 6, pp. 379-407, 2015. https://doi.org/10.1146/annurev-chembioeng-061114-123317

[3] Zabihi, F., Xin, N., Li, S., Jia, J., Cheng, T., Zhao, Y. "Polymeric coating of fluidizing nano-curcumin via anti-solvent supercritical method for sustained release", The Journal of Supercritical Fluids, 89, pp. 99-105, 2014. https://doi.org/10.1016/j.supflu.2014.02.021

[4] Pasquali, I., Bettini, R. "Are pharmaceutics really going supercritical?", International Journal of Pharmaceutics, 364(2), pp. 176-187, 2008.

https://doi.org/10.1016/j.ijpharm.2008.05.014

[5] Martín, V., Romero-Díez, R., Rodríguez-Rojo, S., Cocero, M. J. "Titanium dioxide nanoparticle coating in fluidized bed via supercritical anti-solvent process (SAS)", Chemical Engineering Journal, 279, pp. 425-432, 2015.

https://doi.org/10.1016/j.cej.2015.05.014

[6] Foster, N. R., Gurdial, G. S., Yun, J. S. L., Liong, K. K., Tilly, K. D., Ting, S. S. T., Harcharan, S., Lee, J. H. "Significance of the Crossover Pressure in Solid-Supercritical Fluid Phase Equilibria", Industrial \& Engineering Chemistry Research, 30(8), pp. 1955-1964, 1991. https://doi.org/10.1021/ie00056a044

[7] Teberikler, L., Koseoglu, S., Akgerman, A. "Deoiling of Crude Lecithin Using Supercritical Carbon Dioxide in the Presence of Co-solvents", Journal of Food Science, 66(6), pp. 850-853, 2001. https://doi.org/10.1111/j.1365-2621.2001.tb15185.x

[8] Floris, T., Filippino, G., Scrugli, S., Pinna, M. B. B., Argiolas, F., Argiolas, A., Murru, M. Reverchon, E. "Antioxidant compounds recovery from grape residues by a supercritical antisolvent assisted process", The Journal of Supercritical Fluids, 54(2), pp. 165-170, 2010.

https://doi.org/10.1016/j.supflu.2010.04.006 us to estimate that four additional recrystallization steps are required to exceed $98 \%$ diastereomeric excess.

\section{Acknowledgement}

The project presented in this article is supported by the Országos Tudományos Kutatási Alapprogramok (grant number K108979). We highly appreciate the help of Dr. János Madarász for the possibility of using the powder XRD equipment and his highly valuable advices regarding these analyses. We would like to thank Dr. Imre Miklós Szilágyi for the possibility of using the SEM and Orsolya Kéri for her assistance during the measurements. We would like to thank Klára Sai-Halász for her assistance during the capillary electrophoresis measurements.

[9] Marqués, J. L., Della Porta, G., Reverchon, E., Renuncio, J. A. R., Mainar, A. M. "Supercritical antisolvent extraction of antioxidants from grape seeds after vinification", The Journal of Supercritical Fluids, 82, pp. 238-243, 2013. https://doi.org/10.1016/j.supflu.2013.07.005

[10] Faigl, F., Fogassy, E., Nógrádi, M., Pálovics, E., Schindler, J. "Strategies in optical resolution: a practical guide", Tetrahedron: Asymmetry, 19(5), pp. 519-536, 2008.

https://doi.org/10.1016/j.tetasy.2008.02.004

[11] Faigl, F., Fogassy, E., Nógrádi, M., Pálovics, E., Schindler, J. "Separation of non-racemic mixtures of enantiomers: an essential part of optical resolution", Organic \& Biomolecular Chemistry. 8(5), pp. 947-959, 2010.

https://doi.org/10.1039/b917564d

[12] Pálovics, E., Szeleczky, Z., Fődi, B. B., Faigl, F., Fogassy, E. "Prediction of the efficiency of diastereoisomer separation on the basis of the behaviour of enantiomeric mixtures", RSC Advances, 4(41), pp. 21254-21261, 2014.

https://doi.org/10.1039/c4ra00526k

[13] Székely, E., Simándi, B., Fogassy, E., Kemény, S., Kmecz, I. "Enantioseparation of chiral alcohols by complex formation and subsequent supercritical fluid extraction", Chirality, 15(9), pp. 783-786, 2003.

https://doi.org/10.1002/chir.10295

[14] Székely, E., Simándi, B., Illés, R., Molnár, P., Gebefügi, I., Kmecz, I., Fogassy, E. "Application of supercritical fluid extraction for fractionation of enantiomers", The Journal of Supercritical Fluids, 31(1), pp. 33-40, 2004. https://doi.org/10.1016/j.supflu.2003.09.016

[15] Simándi, B., Keszei, S., Fogassy, E., Sawinsky, J. "Supercritical Fluid Extraction, a Novel Method for Production of Enantiomers", The Journal of Organic Chemistry, 62(13), pp. 4390-4394, 1997. https://doi.org/10.1021/jo960976n

[16] Simándi, B., Keszei, S., Fogassy, E., Kemény, S., Sawinsky, J. "Separation of enantiomers by supercritical fluid extraction", The Journal of Supercritical Fluids, 13(1-3), pp. 331-336, 1998. https://doi.org/10.1016/S0896-8446(98)00068-0 
[17] Bánsághi, Gy., Székely, E., Sevillano, D. M., Juvancz, Z., Simándi, B. "Diastereomer salt formation of ibuprofen in supercritical carbon dioxide", The Journal of Supercritical Fluids, 69, pp. 113-116, 2012. https://doi.org/10.1016/j.supflu.2012.05.016

[18] Bánsághi, Gy., Lőrincz, L., Szilágyi, I. M., Madarász, J., Székely, E. "Crystallization and Resolution of cis -Permethric Acid with Carbon Dioxide Antisolvent", Chemical Engineering \& Technology, 37(8), pp. 1417-1421, 2014. https://doi.org/10.1002/ceat.201300718

[19] Martín, A., Cocero, M. J. J. "Separation of enantiomers by diastereomeric salt formation and precipitation in supercritical carbon dioxide: Application to the resolution of mandelic acid", The Journal of Supercritical Fluids, 40(1), pp. 67-73, 2007. https://doi.org/10.1016/j.supflu.2006.03.018

[20] Kordikowski, A., York, P., Latham, D. "Resolution of ephedrine in supercritical CO2: A novel technique for the separation of chiral drugs", Journal of Pharmaceutical Sciences, 88(8), pp. 786-791, 1999. https://doi.org/10.1021/js980459f

[21] Utczás, M., Székely, E., Tasnádi, G., Monek, É., Vida, L., Forró, E., Fülöp, F. Simándi, B. "Kinetic resolution of 4-phenyl-2-azetidinone in supercritical carbon dioxide", The Journal of Supercritical Fluids, 55(3), pp. 1019-1022, 2011. https://doi.org/10.1016/J.SUPFLU.2010.10.024

[22] Molnár, P., Thorey, P., Bánsághi, Gy., Székely, E., Poppe, L., Tomin, A., Kemény, S., Fogassy, E., Simándi, B. "Resolution of racemic trans-1,2-cyclohexanediol with tartaric acid", Tetrahedron: Asymmetry, 19(13), pp. 1587-1592, 2008. https://doi.org/10.1016/j.tetasy.2008.06.023

[23] Kőrösi, M., Madarász, J., Sohajda, T., Székely, E. "Fast further purification of diastereomeric salts of a nonracemic acid by gas antisolvent fractionation", Chirality, 29(10), pp. 610-615, 2017. https://oi.org/10.1002/chir.22730
[24] Kozma, D., Nyéki, Á., Ács, M., Fogassy, E. "Optical resolution of mandelic acid by cinchonine in different solvents", Tetrahedron: Asymmetry, 5(3), pp. 315-316, 1994. https://doi.org/10.1016/S0957-4166(00)86194-7

[25] Pham, X.-H., Kim, J.-M., Chang, S.-M., Kim, I., Kim, W.-S. "Enantioseparation of D/L-mandelic acid with L-phenylalanine in diastereomeric crystallization", Journal of Molecular Catalysis B: Enzymatic, 60(1-2), pp. 87-92, 2009. https://doi.org/10.1016/j.molcatb.2008.12.023

[26] Saigo, K., Sugiura, I., Shida, I., Tachibana, K., Hasegawa, M. "Optical Resolution of erythro -2-Amino-1,2-diphenylethanol by Reciprocal Crystallization of the Diastereomeric Salts with (-)-Mandelic Acid on Alternate Seeding", Bulletin of the Chemical Society of Japan, 59(9), pp. 2915-2916, 1986. https://doi.org/10.1246/bcsj.59.2915

[27] Tanaka, K., Fukuoka, T., Shiro, M. "Optical resolution of mandelic acid by complexation with (S)-(+)-alanine", Journal of Chemical Research, 2002(9), pp. 446-447, 2002. https://doi.org/10.3184/030823402103172608

[28] Baar, M. R., Cerrone-Szakal, A. L. "Enantiomeric Resolution of $( \pm)$-Mandelic Acid by (1R,2S)-(-)-Ephedrine. An Organic Chemistry Laboratory Experiment Illustrating Stereoisomerism", Journal of Chemical Education, 82(7), p. 1040, 2005. https://oi.org/10.1021/ed082p1040

[29] Leu, A.-D., Chung, S. Y.-K., Robinson, D. B. "The equilibrium phase properties of (carbon dioxide + methanol)", The Journal of Chemical Thermodynamics, 23(10), pp. 979-985, 1991. https://doi.org/10.1016/S0021-9614(05)80178-8

[30] Liu, J., Qin, Z., Wang, G., Hou, X., Wang, J. "Critical Properties of Binary and Ternary Mixtures of Hexane + Methanol, Hexane + Carbon Dioxide, Methanol + Carbon Dioxide, and Hexane + Carbon Dioxide + Methanol", Journal of Chemical \& Engineering Data, 48(6), pp. 1610-1613, 2003. https://doi.org/10.1021/JE034127Q 